\title{
Survival Outcome of Combined GnRH Agonist and Tamoxifen Is Comparable to That of Sequential Adriamycin and Cyclophosphamide Chemotherapy Plus Tamoxifen in Premenopausal Patients with Lymph-Node-Negative, Hormone-Responsive, HER2-Negative, T1-T2 Breast Cancer
}

\author{
Guiyun Sohn, MD ${ }^{1}$ \\ Sei Hyun Ahn, MD, PhD ${ }^{1}$ \\ Hee Jeong Kim, $\mathrm{PhD}^{1}$ \\ Byung-Ho Son, $\mathrm{PhD}^{1}$ \\ Jong Won Lee, $\mathrm{PhD}^{1}$ \\ Beom Seok Ko, PhD' \\ Yura Lee, MD \\ Sae Byul Lee, MD' \\ Seunghee Baek, $\mathrm{PhD}^{2}$
}

\begin{abstract}
Purpose
The purpose of this study was to compare treatment outcomes between combined gonadotropin-releasing hormone agonist and tamoxifen $(\mathrm{GnRHa}+\mathrm{T})$ and sequential adriamycin and cyclophosphamide chemotherapy and tamoxifen (AC->T) in premenopausal patients with hormone-responsive, lymph-node-negative breast cancer.
\end{abstract}

\section{Materials and Methods}

In total, 994 premenopausal women with T1-T2, lymph-node-negative, hormone-receptorpositive, HER2-negative breast cancer between January 2003 and December 2008 were included in this retrospective cohort study. GnRHa+T and AC->T were administered to 608 patients (61.2\%) and 386 patients (38.8\%), respectively. Propensity score matching and inverse probability weighting were applied to the original cohort, and 260 patients for each treatment arm were included in the final analysis. Recurrence-free, cancer-specific, and overall survival was compared between the two treatment groups.

\section{Results}

A total of 994 patients were followed up for a median of 7.4 years (range, 0.5 to 11.4 years). The 5-year follow-up rate was $98.7 \%$, and 13 patients were lost to follow-up. In propensitymatched cohorts $(n=520)$, there was no difference in recurrence-free, cancer-specific, and overall survival rates between the two treatment groups $(p=0.306, p=0.212$, and $p=0.102$, respectively), and this was maintained after applying inverse probability weighting.

\section{Conclusion}

$\mathrm{GnRHa}+\mathrm{T}$ is a reasonable alternative to AC->T in patients with premenopausal, hormoneresponsive, HER2-negative, lymph-node-negative, T1-T2 breast cancer.
Correspondence: Sei Hyun Ahn, MD, PhD Department of Surgery, Asan Medical Center, University of Ulsan College of Medicine, 88 Olympic-ro 43-gil, Songpa-gu,

Seoul 05505, Korea

Tel: 82-2-3010-3480

Fax: 82-2-474-9027

E-mail: ahnsh@amc.seoul.kr

Received November 18, 2015

Accepted March 22, 2016

Published Online April 6, 2016
Key words

Breast neoplasms, Premenopause,

Chemotherapy, Drug therapy, Tamoxifen

\section{Introduction}

Approximately $60 \%$ of breast cancers in premenopausal women reportedly express the estrogen receptor (ER) and / or the progesterone receptor (PR) [1]; the actual prevalence rates in Korea are $69.9 \%$ and $58.3 \%$, respectively [2]. The goal of adjuvant hormonal therapy in hormone-responsive breast cancer patients is to reduce the availability of estrogen to cancer cells, which can be achieved by blocking ERs with drugs such as tamoxifen, suppressing estrogen synthesis using a gonadotropin-releasing hormone $(\mathrm{GnRH})$ agonist, or surgi$\mathrm{cal} /$ radiological removal of ovaries. Among these treatments, the role and efficacy of ovarian suppression with a GnRH agonist remains to be fully defined. Based on the recently published results of the Suppression of Ovarian Function Trial (SOFT), it was concluded that addition of ovarian suppression to tamoxifen does not provide significant benefit in premenopausal patients with breast cancer. However, the addition of ovarian suppression improves dis- 
ease outcomes in women who remain premenopausal after chemotherapy [3]. On the other hand, several trials have shown that ovarian suppression or ablation can exert effects similar to that of chemotherapy in the treatment of ER-positive breast cancer in premenopausal women [4-7]. In addition, because it is widely documented that patients treated with a GnRH agonist alone showed a better quality of life than patients treated with chemotherapy, a few studies have evaluated GnRH agonists as substitutes for chemotherapy in hormone-responsive breast cancer patients [8-12]. In their 7-year follow-up of the French Adjuvant Study Group 06 randomized trial, Roche et al. [13] reported that combining GnRH agonist and tamoxifen (GnRHa+T) and epirubicinbased chemotherapy without hormonal therapy showed similar 7-year disease-free survival and overall survival (OS) rates in premenopausal patients with N1, early breast cancer. Similarly, Kim et al. [14] concluded that GnRHa+T can be an alternative treatment option to sequential adriamycin and cyclophosphamide (AC) chemotherapy and tamoxifen $(\mathrm{AC}->\mathrm{T})$ in premenopausal patients with hormone receptorpositive, hormone-responsive, lymph-node-negative (N0) breast cancer.

The primary aim of this retrospective study was to compare survival outcomes in premenopausal patients with T1-T2, hormone-responsive, HER2-negative breast cancer between $\mathrm{GnRHa}+\mathrm{T}$ for 2 years and $\mathrm{AC}-\mathrm{T}$.

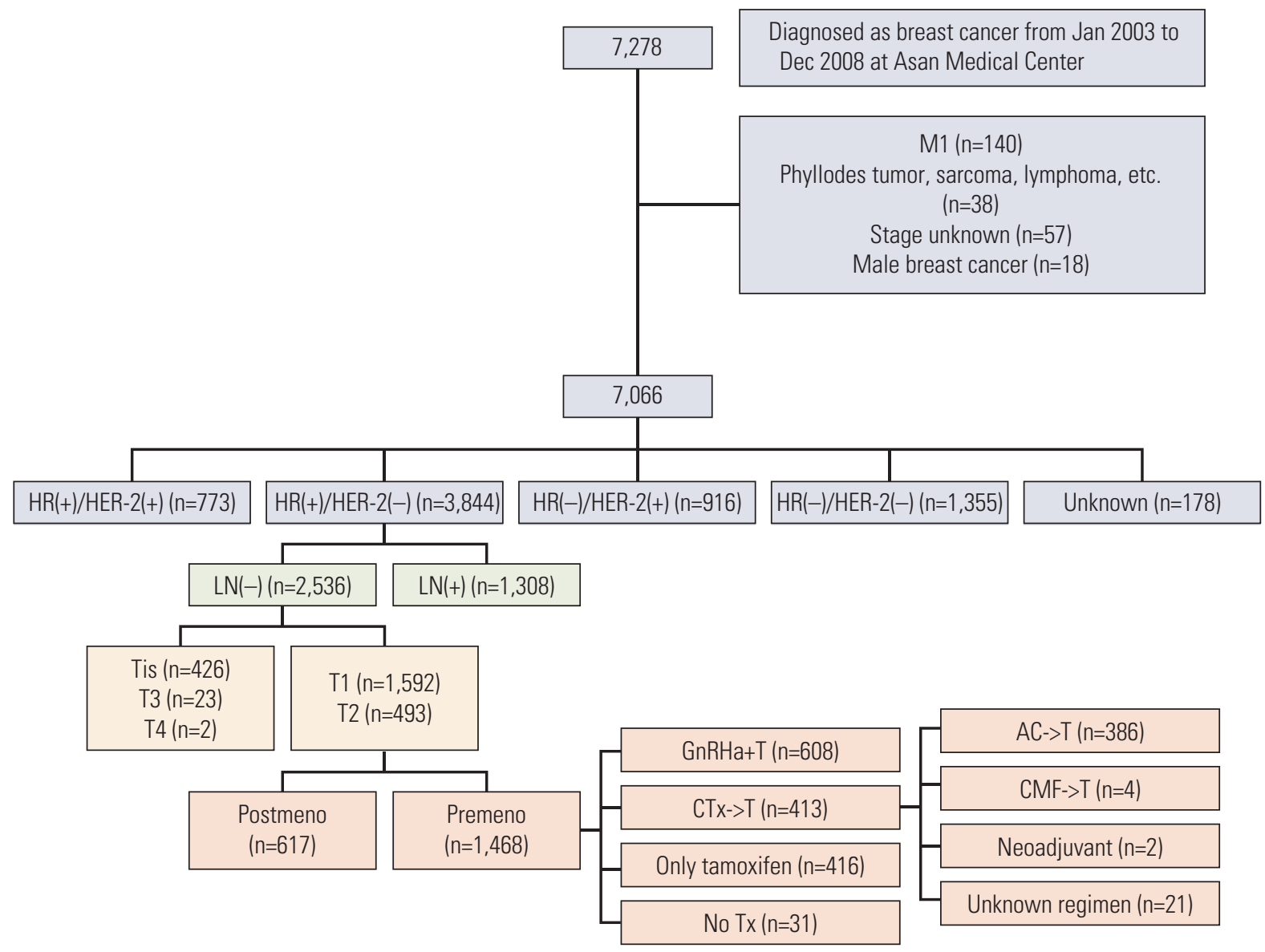

Fig. 1. Inclusion and exclusion diagram. HR, hormone receptor; LN, lymph node; GnRHa+T, combined gonadotropinreleasing hormone agonist and tamoxifen; AC- $>\mathrm{T}$, sequential adriamycin and cyclophosphamide chemotherapy and tamoxifen; $\mathrm{CT} x->\mathrm{T}$, chemotherapy followed by tamoxifen; $\mathrm{CMF}-\mathrm{T}$, sequential cyclophosphamide, methotrexate, 5 -fluorouracil chemotherapy, and tamoxifen; Tx, treatment; Premeno, premenopause; Postmeno, postmenopause. 
Table 1. Characteristics of the overall and the propensity-matched cohorts

\begin{tabular}{|c|c|c|c|c|c|c|}
\hline \multirow[b]{2}{*}{ Variable } & \multicolumn{3}{|c|}{ Overall cohorts } & \multicolumn{3}{|c|}{ Propensity-matched cohort } \\
\hline & $\begin{array}{c}\text { GnRHa+T } \\
(n=608)\end{array}$ & $\begin{array}{l}\text { AC }->T \\
(n=386)\end{array}$ & p-value & $\begin{array}{c}\text { GnRHa+T } \\
(n=260)\end{array}$ & $\begin{array}{l}A C->T \\
(n=260)\end{array}$ & p-value ${ }^{a)}$ \\
\hline Age (yr) & $44.79 \pm 4.9$ & $42.52 \pm 6.69$ & $<0.001$ & $43.83 \pm 5.37$ & $43.47 \pm 6.18$ & 0.466 \\
\hline \multicolumn{7}{|c|}{ Operation method } \\
\hline BCS & $462(76)$ & $217(56.2)$ & $<0.001$ & $172(66.2)$ & $167(64.2)$ & 0.622 \\
\hline Mastectomy & $146(24)$ & $168(43.5)$ & & 88 (33.9) & $93(35.8)$ & \\
\hline \multicolumn{7}{|l|}{ Nuclear grade } \\
\hline 1 & $59(10.1)$ & $33(9.1)$ & $<0.001$ & $21(8.6)$ & $21(8.5)$ & 0.994 \\
\hline 2 & $448(76.5)$ & $241(66.2)$ & & $179(73.4)$ & $181(73.6)$ & \\
\hline 3 & $79(13.5)$ & $90(24.7)$ & & $44(18)$ & $44(17.9)$ & \\
\hline \multicolumn{7}{|c|}{ Histologic grade } \\
\hline 1 & $72(12.4)$ & $36(9.8)$ & 0.002 & $26(10.6)$ & $27(11)$ & 0.726 \\
\hline 2 & $431(74.2)$ & $249(67.5)$ & & $178(72.7)$ & $174(70.7)$ & \\
\hline 3 & $78(13.4)$ & $84(22.8)$ & & $41(16.7)$ & $45(18.3)$ & \\
\hline \multicolumn{7}{|c|}{ Estrogen receptor } \\
\hline+ & $573(94.2)$ & $334(86.5)$ & $<0.001$ & $239(91.9)$ & $241(92.7)$ & 0.723 \\
\hline- & $35(5.8)$ & $52(13.5)$ & & $21(8)$ & $19(7.3)$ & \\
\hline \multicolumn{7}{|c|}{ Progesterone receptor } \\
\hline+ & $561(92.3)$ & $333(86.3)$ & 0.002 & $233(89.6)$ & $231(88.9)$ & 0.781 \\
\hline- & $47(7.7)$ & $53(13.7)$ & & $27(10.4)$ & $29(11.2)$ & \\
\hline \multicolumn{7}{|l|}{ Tumor stage } \\
\hline $\mathrm{T} 1 \mathrm{a}+\mathrm{T} 1 \mathrm{~b}$ & $97(16)$ & $18(4.7)$ & $<0.001$ & $29(11.2)$ & $18(6.9)$ & 0.241 \\
\hline T1c & $396(65.1)$ & $163(42.2)$ & & 135 (51.9) & $140(53.8)$ & \\
\hline $\mathrm{T} 2$ & $115(18.9)$ & $205(53.1)$ & & $96(36.9)$ & $102(39.2)$ & \\
\hline \multicolumn{7}{|l|}{ HER2 } \\
\hline- & $312(51.3)$ & $202(52.3)$ & 0.896 & $128(49.2)$ & $137(52.7)$ & 0.448 \\
\hline+ & $296(48.7)$ & $184(47.7)$ & & $132(50.8)$ & $123(47.3)$ & \\
\hline \multicolumn{7}{|l|}{ p53 } \\
\hline- & $430(84.8)$ & $253(71.9)$ & $<0.001$ & $195(75)$ & $195(75)$ & $>0.999$ \\
\hline+ & $77(15.2)$ & $99(28.1)$ & & $65(25)$ & $65(25)$ & \\
\hline
\end{tabular}

Values are presented as mean \pm standard deviation or number $(\%)$. GnRHa $+\mathrm{T}$, combined gonadotropin-releasing hormone agonist and tamoxifen; AC->T, sequential adriamycin and cyclophosphamide chemotherapy and tamoxifen; BCS, breastconserving surgery. ${ }^{a)} \mathrm{p}$-values are based on the paired $\mathrm{t}$ test for continuous variables and on McNemar's test for categorical variables.

\section{Materials and Methods}

\section{Study design}

Between January 2003 and December 2008, 7,278 patients were diagnosed with and registered as having breast cancer at Asan Medical Center, Seoul, Korea; 2,085 patients had T1T2, N0, hormone-responsive, HER2-negative breast cancer, and 1,468 were premenopausal. GnRHa+T and AC->T were administered to 608 and 386 patients, respectively, as a postoperative adjuvant breast cancer treatment; therefore, 994 patients were included in the final analysis (Fig. 1). Pre- menopausal status was confirmed in those who had menstruated less than 1 year before surgery or had a premenopausal follicle-stimulating hormone level of less than 30 IU/mL. Premenopausal patients with T1-T2, N0, M0, hormone-responsive, HER2-negative breast cancer were provided with complete information about the efficacies and benefits of $\mathrm{GnRHa}+\mathrm{T}$ and $\mathrm{AC}->\mathrm{T}$, and each patient then chose her preferred regimen. Patients in the AC->T group received four cycles of AC chemotherapy $\left(60 \mathrm{mg} / \mathrm{m}^{2}\right.$ adriamycin intravenously plus $60 \mathrm{mg} / \mathrm{m}^{2}$ cyclophosphamide intravenously every 21 days) followed by tamoxifen ( $20 \mathrm{mg} /$ day for 5 years or until relapse or intolerance). Patients in the $\mathrm{GnRHa}+\mathrm{T}$ group received $\mathrm{GnRH}$ agonist $(3.6 \mathrm{mg} / \mathrm{kg}$ gosere- 
Table 2. HRs for clinical outcomes among overall, T1a+T1b group, T1c group, T2 group, and the propensity-matched patients

\begin{tabular}{|c|c|c|c|c|c|}
\hline Parameter & Treatment & DF & HR & $95 \% \mathrm{CI}$ & p-value \\
\hline \multicolumn{6}{|c|}{ Overall cohort } \\
\hline \multirow[t]{2}{*}{ RFS } & $\mathrm{GnRHa}+\mathrm{T}$ & 1 & 0.791 & $0.488-1.282$ & 0.342 \\
\hline & $\mathrm{AC}->\mathrm{T}$ & & 1 & & \\
\hline \multirow[t]{2}{*}{ CSS } & GnRHa+T & 1 & 0.249 & $0.079-0.788$ & 0.018 \\
\hline & $\mathrm{AC}->\mathrm{T}$ & & 1 & & \\
\hline \multirow[t]{2}{*}{ OS } & $\mathrm{GnRHa}+\mathrm{T}$ & 1 & 0.377 & $0.166-0.857$ & 0.020 \\
\hline & $\mathrm{AC}->\mathrm{T}$ & & 1 & & \\
\hline \multicolumn{6}{|c|}{$\mathrm{T} 1 \mathrm{a}+\mathrm{T} 1 \mathrm{~b}$ group } \\
\hline \multirow[t]{2}{*}{ RFS } & $\mathrm{GnRHa}+\mathrm{T}$ & 1 & 0.299 & $0.071-1.256$ & 0.099 \\
\hline & $\mathrm{AC}->\mathrm{T}$ & & 1 & & \\
\hline \multirow[t]{2}{*}{ OS } & $\mathrm{GnRHa}+\mathrm{T}$ & 1 & 0.180 & $0.011-2.884$ & 0.226 \\
\hline & $\mathrm{AC}->\mathrm{T}$ & & 1 & & \\
\hline \multicolumn{6}{|l|}{ T1c group } \\
\hline \multirow[t]{2}{*}{ RFS } & $\mathrm{GnRHa}+\mathrm{T}$ & 1 & 1.090 & $0.479-2.478$ & 0.838 \\
\hline & $A C->T$ & & 1 & & \\
\hline \multirow[t]{2}{*}{ CSS } & $\mathrm{GnRHa}+\mathrm{T}$ & 1 & 0.405 & $0.082-2.006$ & 0.268 \\
\hline & $\mathrm{AC}->\mathrm{T}$ & & 1 & & \\
\hline \multirow[t]{2}{*}{ OS } & $\mathrm{GnRHa}+\mathrm{T}$ & 1 & 0.480 & $0.143-1.164$ & 0.094 \\
\hline & $A C->T$ & & 1 & & \\
\hline \multicolumn{6}{|l|}{$\mathrm{T} 2$ group } \\
\hline \multirow[t]{2}{*}{ RFS } & $\mathrm{GnRHa}+\mathrm{T}$ & 1 & 1.090 & $0.519-2.290$ & 0.820 \\
\hline & $\mathrm{AC}->\mathrm{T}$ & & 1 & & \\
\hline \multirow[t]{2}{*}{ CSS } & $\mathrm{GnRHa}+\mathrm{T}$ & 1 & 0.280 & $0.034-2.294$ & 0.235 \\
\hline & $\mathrm{AC}->\mathrm{T}$ & & 1 & & \\
\hline \multirow[t]{2}{*}{ OS } & $\mathrm{GnRHa}+\mathrm{T}$ & 1 & 0.280 & $0.034-2.294$ & 0.235 \\
\hline & $\mathrm{AC}->\mathrm{T}$ & & 1 & & \\
\hline \multicolumn{6}{|c|}{ Propensity-matched cohort } \\
\hline \multirow[t]{2}{*}{ RFS } & GnRHa+T & 1 & 1.461 & $0.707-3.021$ & 0.306 \\
\hline & $\mathrm{AC}->\mathrm{T}$ & & 1 & & \\
\hline \multirow[t]{2}{*}{ CSS } & GnRHa+T & 1 & 0.247 & $0.028-2.223$ & 0.212 \\
\hline & $\mathrm{AC}->\mathrm{T}$ & & 1 & & \\
\hline \multirow[t]{2}{*}{ OS } & GnRHa+T & 1 & 0.333 & $0.089-1.243$ & 0.102 \\
\hline & $\mathrm{AC}->\mathrm{T}$ & & 1 & & \\
\hline
\end{tabular}

HR, hazard ratio; DF, degree of freedom; CI, confidence interval; RFS, recurrence-free survival; GnRHa $+\mathrm{T}$, combined gonadotropin-releasing hormone agonist and tamoxifen; $\mathrm{AC}->\mathrm{T}$, sequential adriamycin and cyclophosphamide chemotherapy and tamoxifen; CSS, cancer-specific survival; OS, overall survival.

lin or $3.75 \mathrm{mg} / \mathrm{kg}$ leuprorelin) for 2 years and tamoxifen simultaneously for 5 years.

The concentrations of hormone receptors in formalin-fixed, paraffin-embedded tissue sections of the primary tumors were determined using primary antibodies against ER (1:50, Dinona, Seoul, Korea) and PR (1:100, Dinona) in a Benchmark automatic immunostaining device (Ventana Medical Systems, Tucson, AZ). Nuclear staining was scored as 0 (negative), 1-3 (weakly positive), 4 or 5 (intermediately positive), or 6 or 7 (strong positive), while hormone receptor positivity was defined as a score over 4 . HER2 status was confirmed by immunohistochemistry, and HER2 receptor negativity was defined as negative, $1+$ or $2+$.

\section{Statistical analysis}

The recurrence-free survival (RFS) period was defined as the time from the operation to disease recurrence or death (whichever occurred first), the cancer-specific survival (CSS) period was defined as the time from the operation to cancercaused death, and the OS period was defined as the time from the operation to death from any cause. Patient charac- 
teristics were compared between treatment groups using Pearson's chi-square test. RFS, CSS, and OS were assessed using Kaplan-Meier curves and compared using a log-rank test. The Cox proportional hazards (PH) model was used for calculation of the adjusted hazard ratios of the treatment effect while accounting for the effects of patient characteristics and other significant prognostic factors. Variables were assessed on a univariate basis, and factors with a significance probability of $\leq 0.25$ were included in multivariate analysis and selected using backward elimination.

To reduce the effect of selection bias when assigning patients to either GnRHa+T or AC-> T, a propensity score (PS)-based analysis was also performed to produce a rigorous adjustment of the baseline characteristics of the patients. PSs were estimated using multiple logistic regression analysis with all pre-specified covariates listed in Table 1. Model discrimination was assessed using $c$-statistics $(c=0.773)$, and model calibration was performed using Hosmer-Lemeshow statistics $(\mathrm{p}=0.152)$. Both treatment groups were matched based on their estimated PSs, with caliper widths of 0.1. The balance of baseline covariates was checked by calculating the standardized difference of means. To account for the matched nature of subject selection, a Cox PH model was performed with a sandwich estimator of variance. A Cox PH model was also performed with inverse probability of treatment weighting, called an inverse probability-weighted Cox model, using the PS. The estimated hazards from several methods described above are reported. A probability value of $p \leq 0.05$ indicated statistical significance. Results were analyzed using SPSS ver. 21 for Windows (IBM Co., Armonk, NY) and R 3.0.2 (free software which can be downloaded from http://www.r-project.org) with package 'MatchIt' and 'Survival.'

\section{Results}

\section{Patients and tumor characteristics}

Of the 994 patients, $674(67.8 \%)$ had T1, N0 disease and 320 $(32.2 \%)$ had T2, N0 disease. Among the patients with T1 disease, $493(73.2 \%)$ received GnRHa+T and $181(26.8 \%)$ received $\mathrm{AC}->\mathrm{T}$. Among the patients with $\mathrm{T} 2$ disease, 115 $(35.7 \%)$ received GnRHa+T and $205(64.3 \%)$ received AC->T. Because this is a retrospective study, there is heterogeneity in the patients' age, tumor stage, ER positivity, PR positivity, and histologic and nuclear grade in the two treatment groups of the original cohort. We therefore applied PS matching, which produced 260 matched patients in each treatment arm (Table 1). In these matched cohorts, there were no significant group differences in age, operation method, nuclear and histologic grades, ER positivity, PR positivity, or tumor stage.

\section{Survival analysis}

The 994 patients were followed up for a median of 7.4 years (range, 0.5 to 11.4 years). The 5 -year follow-up rate was $98.7 \%$, with 13 patients lost to follow-up: two patients were lost within 1 year after surgery and six patients within 3 years after surgery. The 5-year RFS rate was 95.9\%; recurrence in 68 patients included 35 patients with loco-regional recurrence and 33 patients with distant metastasis. Among 35 loco-regional recurrences, 18 patients had in-breast recurrences, seven patients had axillary lymph node metastasis, four patients had supraclavicular lymph node metastasis, and six had internal mammary lymph node metastasis. The 5-year CSS and OS rates were $98.9 \%$ and $98.3 \%$, respectively (14 cancer-specific and 25 overall deaths). RFS, CSS, and OS in overall cohort, $\mathrm{T} 1 \mathrm{a}+\mathrm{T} 1 \mathrm{~b}$ group, T1c group, T2 group, and propensity-matched cohorts are shown separately in Table 2. Considering different clinical characteristics between the two treatment groups showing smaller tumor size, low nuclear and histologic grade in the GnRHa+T group, it resulted in favorable CSS and OS for the GnRHa+T group in the overall cohort. However, in subgroup analysis based on tumor size, there was no difference in survival between the two treatment groups.

Of the 520 patients in the propensity-matched cohorts, 34 patients showed recurrence, with five cancer-specific deaths and 12 overall deaths. The survival rate did not differ significantly between the two treatment groups among these propensity-matched patients (Table 2). The Kaplan-Meier survival curves for the two treatment arms in the overall cohort, T1a+T1b group, T1c group, and T2 group are shown in Fig. 2, and the Kaplan-Meier survival curves in propensity-matched cohorts are shown in Fig. 3.

Propensity matching, inverse probability weighting was applied to the original cohort. Results of the Cox regression analysis of RFS, CSS, and OS with application of inverse probability of weighting are shown in Table 3 . There were no group differences in RFS and CSS, but OS was significantly better in the $\mathrm{GnRHa}+\mathrm{T}$ group ( $\mathrm{p}=0.021$ ). Kaplan-Meier estimates between the treatment arms in inverse-probability-weighted cohorts are shown in Fig. 4.

\section{Discussion}

The primary aim of this study was to compare treatment outcomes between GnRHa+T and AC->T in premenopausal 
A
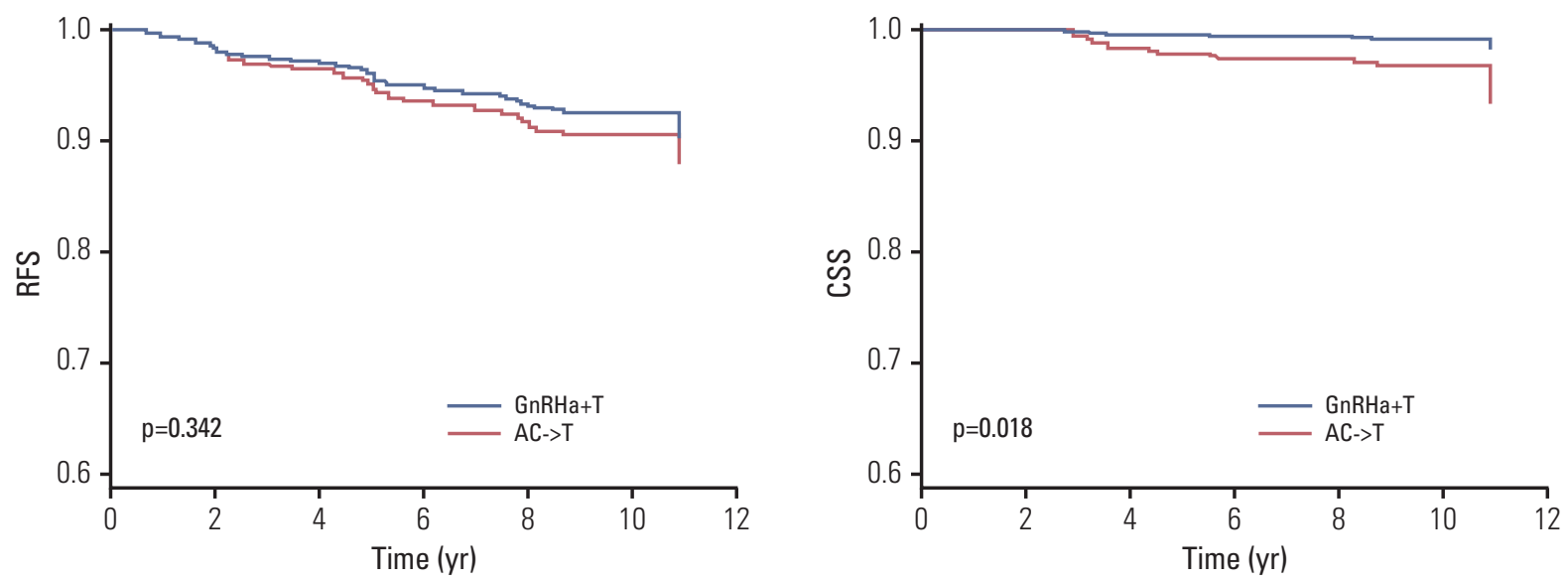

C
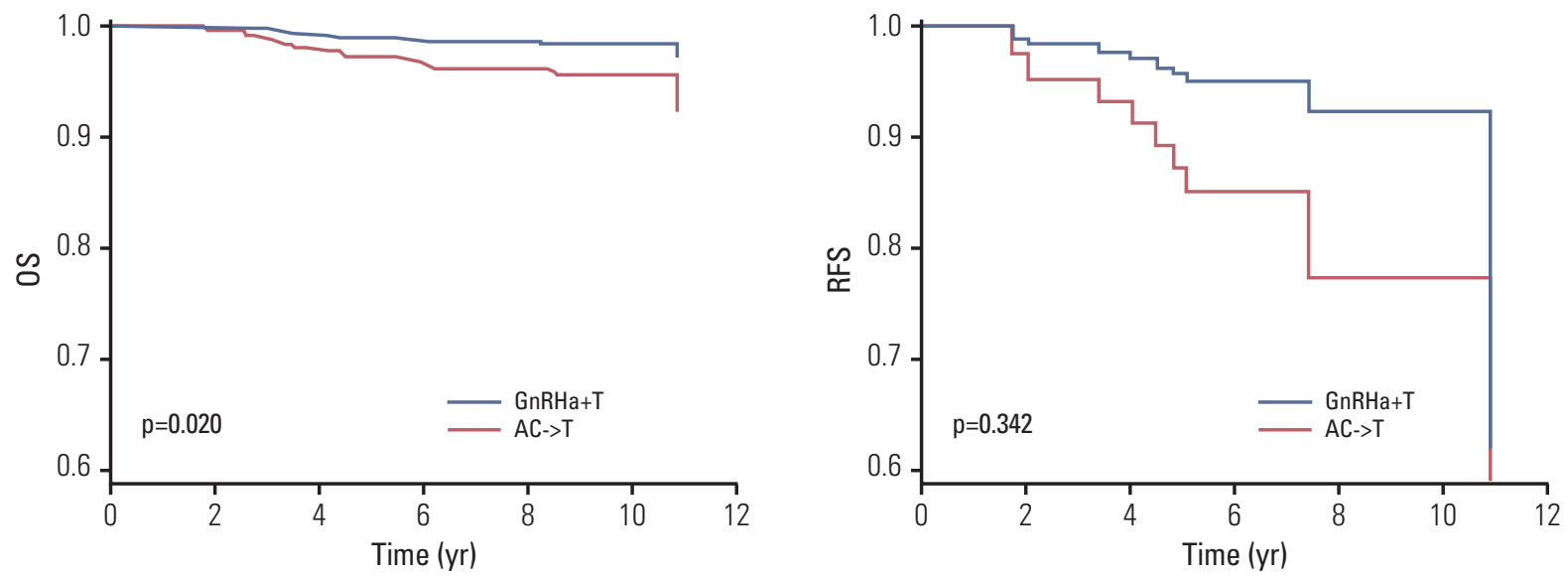

$\mathbf{E}$
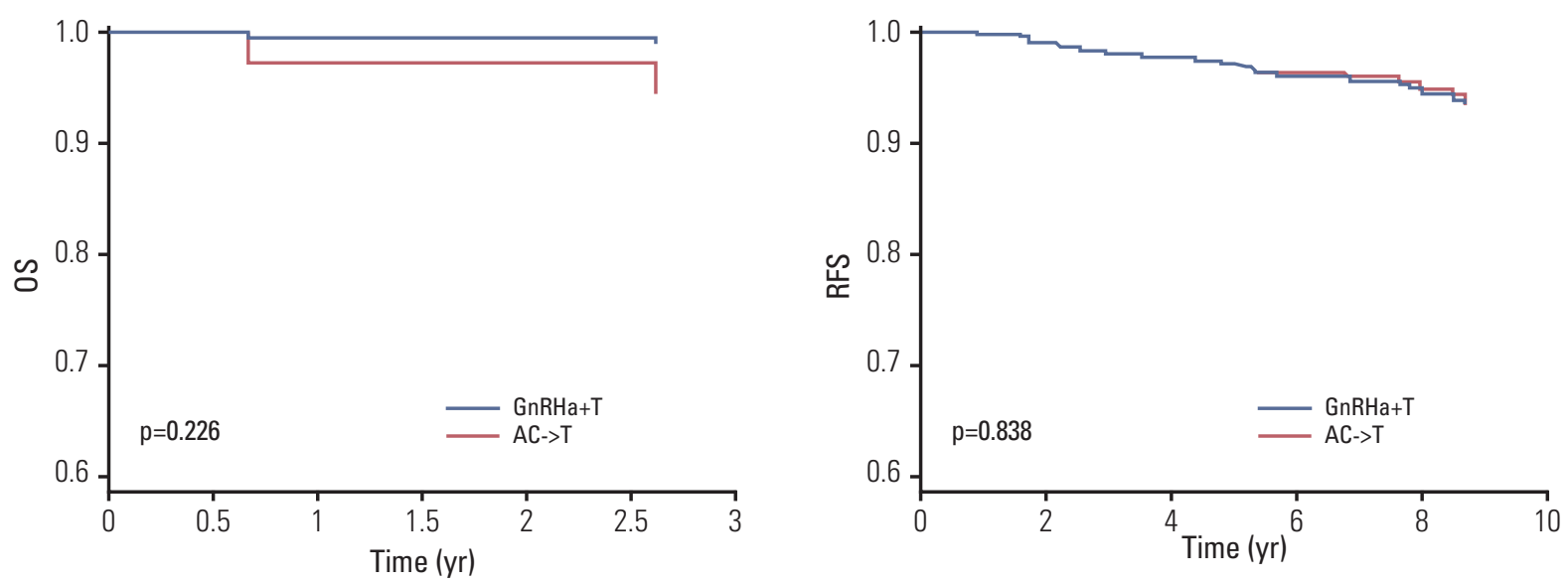

Fig. 2. Recurrence-free survival (RFS) (A), cancer-specific survival (CSS) (B), and overall survival (OS) (C) curves according to treatment arm (combined gonadotropin-releasing hormone agonist and tamoxifen [GnRHa+T] vs. sequential adriamycin and cyclophosphamide chemotherapy and tamoxifen [AC->T]) in overall cohorts ( $\mathrm{n}=994)$. RFS (D) and OS (E) curves according to treatment arm (GnRHa+T vs. AC->T) in the T1a+T1b group (n=115), RFS (F), CSS (G), and OS (H) curves according to treatment arm (GnRHa+T vs. AC- $>$ T) in the T1c group ( $\mathrm{n}=559)$. RFS (I), CSS (J), and OS (K) curves according to treatment arm $(\mathrm{GnRHa}+\mathrm{T}$ vs. $\mathrm{AC}->\mathrm{T})$ in $\mathrm{T} 2$ group $(\mathrm{n}=320)$. (Continued to the next page) 
G
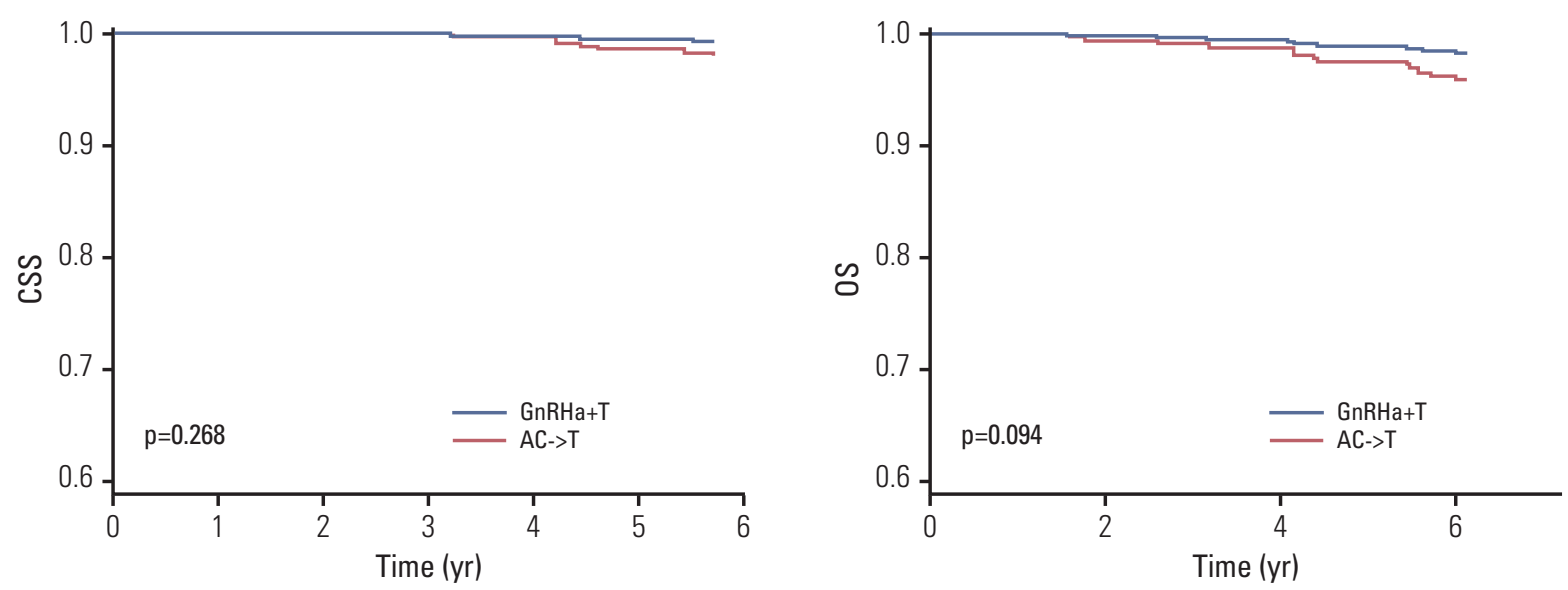

I
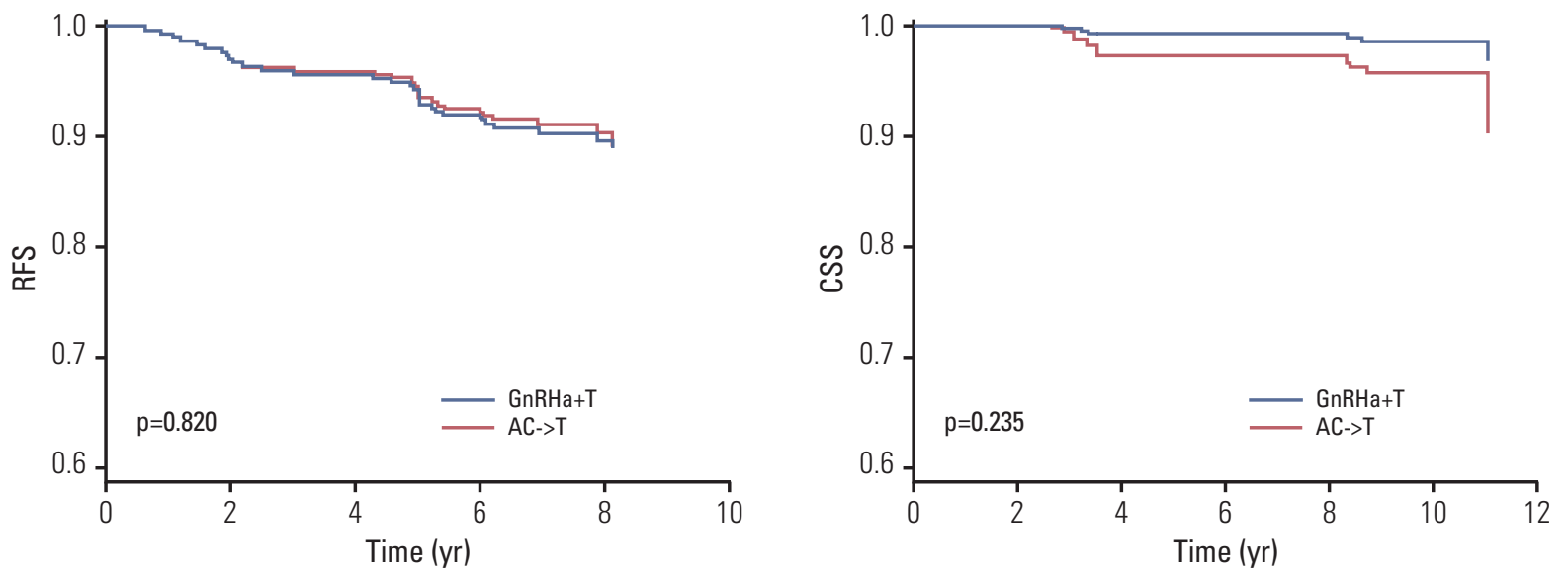

K

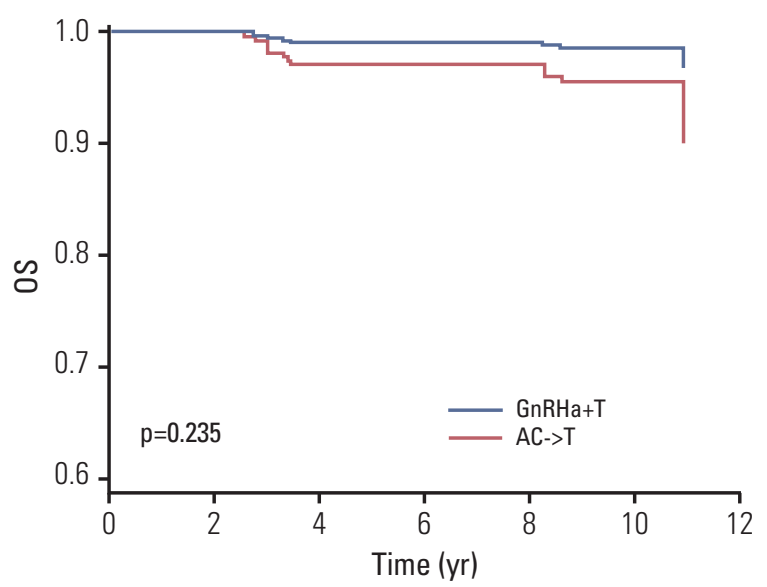

Fig. 2. (Continued from the previous page) 
A
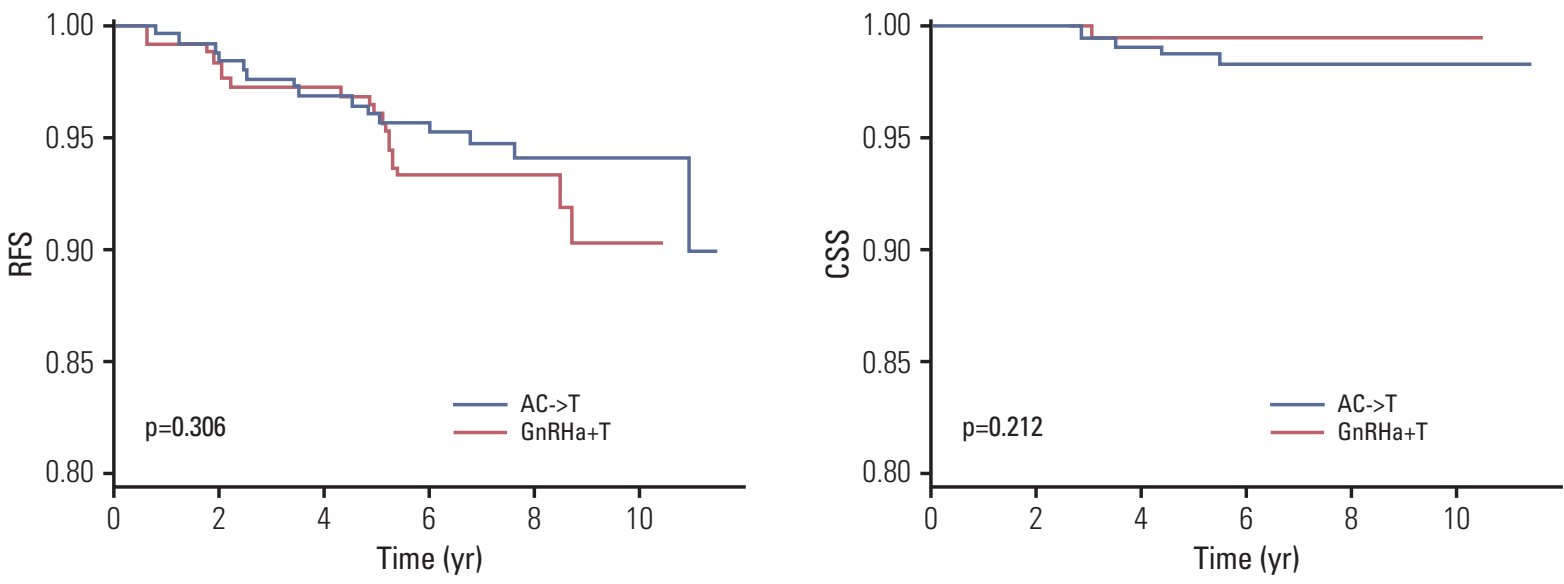

C

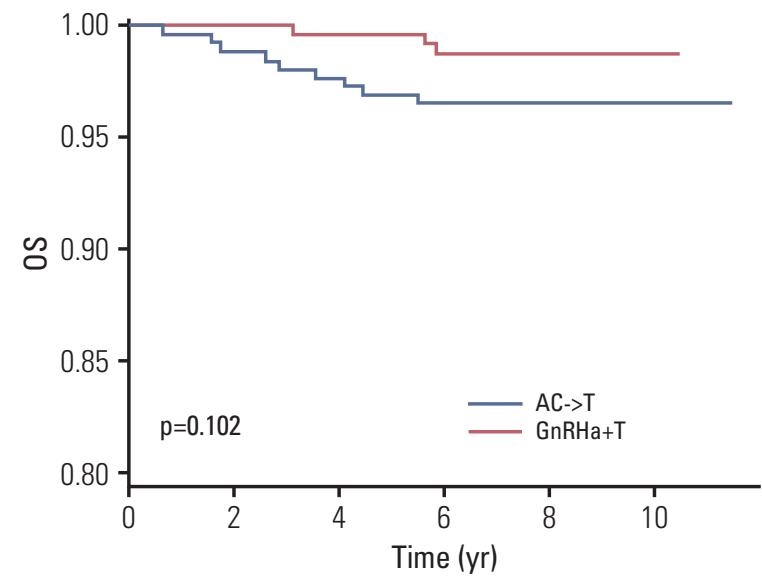

Fig. 3. Recurrence-free survival (RFS) (A), cancer-specific survival (CSS) (B), and overall survival (OS) (C) curves according to treatment arm (combined gonadotropin-releasing hormone agonist and tamoxifen [GnRHa $+\mathrm{T}]$ vs. sequential adriamycin and cyclophosphamide chemotherapy and tamoxifen $[\mathrm{AC}->\mathrm{T}])$ in propensity-matched cohorts $(\mathrm{n}=520)$.

Table 3. HRs for clinical outcomes using inverse probability of weighting among the propensity-matched patients

\begin{tabular}{llcccc} 
Parameter & Treatment & DF & HR & 95\% CI & p-value \\
RFS & GnRHa+T & 1 & 1.196 & $0.692-2.066$ & 0.522 \\
& AC->T & & 1 & & \\
CSS & GnRHa+T & 1 & 0.377 & $0.099-1.442$ & 0.154 \\
OS & AC->T & & 1 & & \\
& GnRHa+T & 1 & 0.333 & $0.131-0.846$ & 0.021 \\
\hline
\end{tabular}

Trimming (by 0.1, > 10) does not affect the data. HR, hazard ratio; DF, degree of freedom; CI, confidence interval; RFS, recurrence-free survival; GnRHa+T, combined gonadotropin-releasing hormone agonist and tamoxifen; $\mathrm{AC}->\mathrm{T}$, sequential adriamycin and cyclophosphamide chemotherapy and tamoxifen; CSS, cancer-specific survival; OS, overall survival. 
A

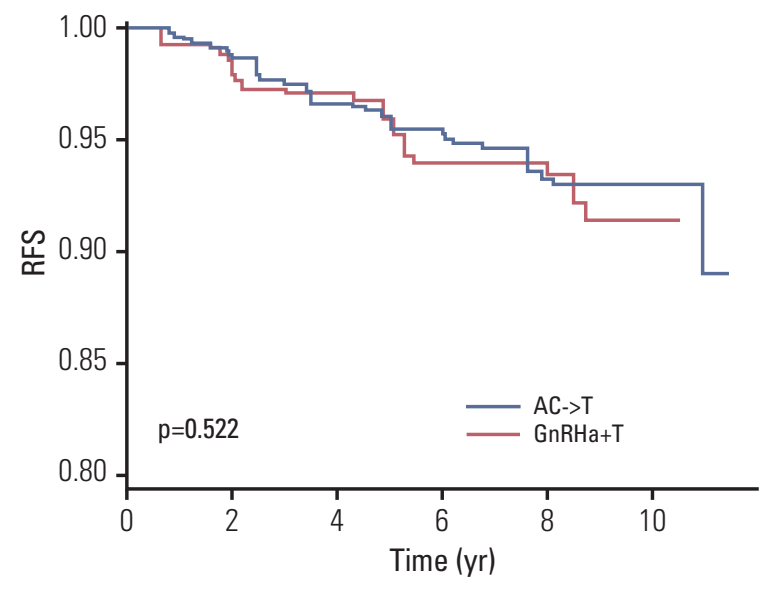

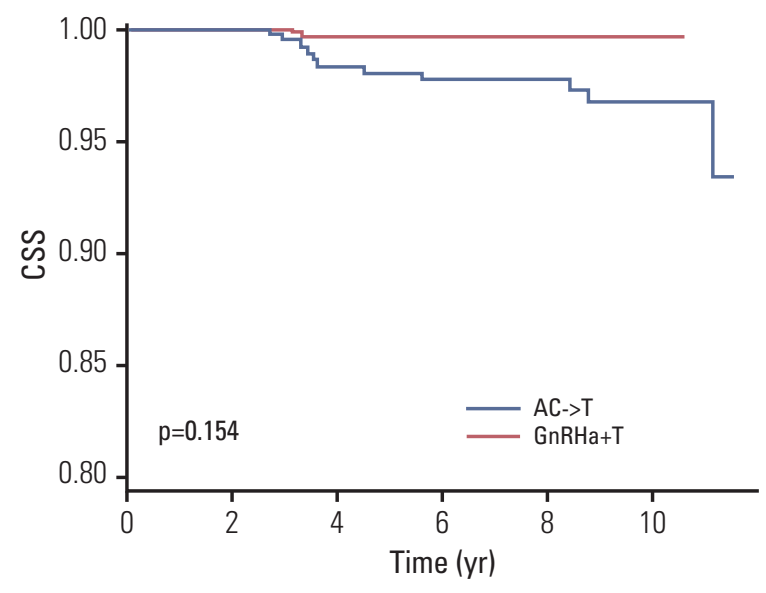

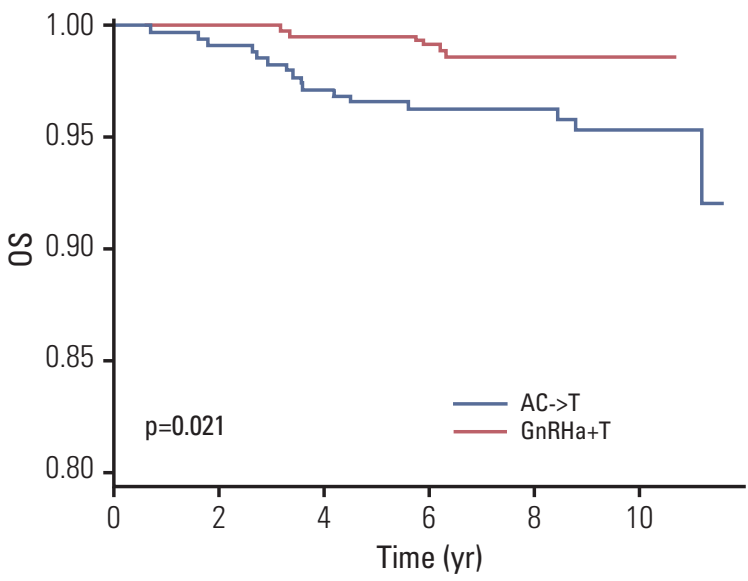

Fig. 4. Recurrence-free survival (RFS) (A), cancer-specific survival (CSS) (B), and overall survival (OS) (C) curves according to treatment arm (combined gonadotropin-releasing hormone agonist and tamoxifen [GnRHa $+\mathrm{T}]$ vs. sequential adriamycin and cyclophosphamide chemotherapy and tamoxifen [AC-> T] ) in inverse-probability-weighted cohorts $(n=520)$.

patients with T1-T2, hormone-responsive, HER2-negative breast cancer. Similar to other studies comparing the efficacies of GnRH agonist and chemotherapy in premenopausal breast cancer patients $[13,14]$, our patients in the GnRHa+T group showed comparable treatment outcomes to those in the AC->T group.

The efficacy of ovarian suppression in premenopausal breast cancer has been addressed in several clinical trials. The Zoladex Early Bresat Cancer Research Association, ZEBRA) trial $[6,15]$ and International Breast Cancer Study Group (IBCSG) VIII [16] trials found similar efficacy for GnRH agonist and cyclophosphamide, methotrexate, 5-fluorouracil chemotherapy chemotherapy in terms of RFS and OS in hormone-responsive early breast cancer. Kim et al. [14] compared the efficacies of $\mathrm{GnRHa}+\mathrm{T}$ and $\mathrm{AC}->\mathrm{T}$ with a median follow-up period of 30 months. Although that was a small, preliminary study with a relatively short follow-up period, the authors concluded that $\mathrm{GnRHa}+\mathrm{T}$ can be an alternative treatment option in premenopausal patients with endocrineresponsive, N0 breast cancer. In their 7-year follow-up of the French Adjuvant Study Group 06 randomized trial, Roche et al. [13] reported similar 7-year RFS and OS rates in premenopausal patients with N1, early breast cancer for GnRHa+T and epirubicin-based chemotherapy. On the other hand, based on SOFT data [3], it was concluded that addition of ovarian suppression to tamoxifen did not provide a significant benefit in the overall population of premenopausal women. However, those authors also stated that in the cohort of women whose risk of recurrence was sufficient to warrant adjuvant chemotherapy and who had premenopausal estra- 
diol levels despite chemotherapy, ovarian suppression in addition to tamoxifen reduced the risk of breast cancer recurrence compared to tamoxifen alone.

The results of previous studies indicate that the addition of ovarian suppression to tamoxifen is not an appropriate routine treatment option for all premenopausal patients with hormone-responsive breast cancer. Instead, only premenopausal patients with hormone-responsive breast cancer who would benefit the most from ovarian suppression in addition to tamoxifen should be selected. In this group of patients, the efficacy of GnRH agonist is similar to that of chemotherapy as reported in previous studies, and further replaces chemotherapy as an alternative. As in the current study, premenopausal patients with T1-T2, hormone-responsive, HER2negative breast cancer might be good candidates. We found no statistically significant difference in RFS and CSS between our GnRHa+T and AC->T groups in premenopausal patients with hormone-responsive, early breast cancer. However, a large-scale, randomized controlled study is still required for prospective comparison of the efficacies of $\mathrm{GnRHa}+\mathrm{T}$ and AC- $>$ T.

As described above, only 68 of our 994 patients showed recurrence, with a 5-year RFS of $95.9 \%$; there were 15 cancerspecific deaths with a 5-year CSS of $98.9 \%$ and 25 overall deaths with a 5-year OS of $98.3 \%$. In designing a randomized controlled study for separate statistical confirmation of the presence of non-inferiority within 1\%, 3\%, and 5\% margins, total sample sizes of 4,561, 1,650, and 964, respectively, would be required for RFS, with sizes of 2,423, 1,370, and 1,019 for CSS. Therefore, a long accrual time as well as multicenter collaboration would be required to prospectively confirm the equivalence, non-inferiority, or superiority of $\mathrm{GnRHa}+\mathrm{T}$ versus AC->T. Until these prospective data are obtained, large-scale retrospective data might provide valuable information on effective treatments in this specific group of patients. To the best of our knowledge, the current study included the largest series of retrospective data comparing $\mathrm{GnRHa}+\mathrm{T}$ to $\mathrm{AC}->\mathrm{T}$ in premenopausal patients with hormone-responsive, T1-T2, N0 breast cancer.

The optimal treatment duration of GnRH agonist is also controversial. In the current study, patients who chose GnRHa+T treatment received GnRH agonist for 2 years. Shiba et al. [17] reported that adjuvant leuprorelin treatment for 3 or more years with tamoxifen showed a survival benefit and safety profile similar to that for 2 years in premenopausal patients with endocrine-responsive breast cancer in a randomized controlled study. Similar to our results, several trials using $\mathrm{GnRH}$ agonists for 2 years reported no differences in treatment outcomes between $\mathrm{GnRH}$ agonists and chemotherapy $[6,13,16,18]$. On the other hand, trials showing a superiority of hormonal blockade over chemotherapy used GnRH agonists for 2 or 3 years combined with tamoxifen for
5 years or tamoxifen with ovarian ablation $[19,20]$. The patients included in SOFT [3] had completed 5 years of ovarian suppression. The treatment duration is an important issue since the duration of $\mathrm{GnRH}$-agonist treatment determines the duration of amenorrhea. Swain et al. [21] proposed that a longer duration of amenorrhea was associated with improved survival regardless of the chemotherapy regimen and estrogen receptor status. In accordance with these findings, one of the groups in SOFT [3] in which a survival benefit was found by addition of ovarian suppression to tamoxifen comprised patients with premenopausal estradiol levels despite chemotherapy, with ovarian suppression in addition to tamoxifen reducing the risk of breast cancer recurrence compared to tamoxifen alone. This finding implies that the duration of amenorrhea is an important prognostic factor regardless of the type of adjuvant therapy. In their meta-analysis, the Early Breast Cancer Overview group $[22,23]$ concluded that $\mathrm{GnRH}$ agonists showed an additional benefit when administered after chemotherapy, either alone or with tamoxifen, in women aged 40 years or younger, in whom chemotherapy is less likely to induce permanent amenorrhea than in older women. Several studies have reported significant improvements in relapse and survival in premenopausal women with breast cancer who develop amenorrhea after chemotherapy compared with those who did not $[24,25]$. In the current study, in the subset of patients younger than 39 years, the 5 -year CSS and OS rates appeared to be better in the $\mathrm{GnRHa}+\mathrm{T}$ group than in the $\mathrm{AC}->\mathrm{T}$ group. Therefore, future research should confirm the optimal duration of GnRH-agonist treatment and whether maintaining amenorrhea for a longer period can provide a survival benefit.

The limitation of this study is the retrospective nature. The clinical and tumor characteristics of the two treatment groups are not evenly distributed. Therefore, results of direct comparison between two treatment groups might be uncertain. PS matching and inverse probability weighting was applied to overcome this limitation to minimize the heterogeneity of the treatment group.

\section{Conclusion}

In conclusion, the findings of this study suggest that GnRHa+T is a comparable alternative to $A C->T$ in premenopausal patients with hormone-responsive, HER2-negative, N0, T1-T2 breast cancer. 


\section{Conflicts of Interest}

Conflict of interest relevant to this article was not reported.

\section{References}

1. Schmid P, Untch M, Kosse V, Bondar G, Vassiljev L, Tarutinov $\mathrm{V}$, et al. Leuprorelin acetate every-3-months depot versus cyclophosphamide, methotrexate, and fluorouracil as adjuvant treatment in premenopausal patients with node-positive breast cancer: the TABLE study. J Clin Oncol. 2007;25:2509-15.

2. Ko BS, Noh WC, Kang SS, Park BW, Kang EY, Paik NS, et al. Changing patterns in the clinical characteristics of korean breast cancer from 1996-2010 using an online nationwide breast cancer database. J Breast Cancer. 2012;15:393-400.

3. Francis PA, Regan MM, Fleming GF. Adjuvant ovarian suppression in premenopausal breast cancer. N Engl J Med. 2015; 372:1673.

4. Adjuvant ovarian ablation versus CMF chemotherapy in premenopausal women with pathological stage II breast carcinoma: the Scottish trial. Scottish Cancer Trials Breast Group and ICRF Breast Unit, Guy's Hospital, London. Lancet. 1993; 341:1293-8.

5. Boccardo F, Guglielmini P, Parodi A, Rubagotti A. Chemotherapy versus tamoxifen versus chemotherapy plus tamoxifen in node-positive, oestrogen receptor-positive breast cancer patients: very late results of the 'gruppo di ricerca per la chemio-ormonoterapia adiuvante (GROCTA)' 01-Trial in early breast cancer. Breast Cancer Res Treat. 2011;126:653-61.

6. Jonat W, Kaufmann M, Sauerbrei W, Blamey R, Cuzick J, Namer $M$, et al. Goserelin versus cyclophosphamide, methotrexate, and fluorouracil as adjuvant therapy in premenopausal patients with node-positive breast cancer: The Zoladex Early Breast Cancer Research Association Study. J Clin Oncol. 2002;20:4628-35.

7. von Minckwitz G, Graf E, Geberth M, Eiermann W, Jonat W, Conrad B, et al. CMF versus goserelin as adjuvant therapy for node-negative, hormone-receptor-positive breast cancer in premenopausal patients: a randomised trial (GABG trial IVA-93). Eur J Cancer. 2006;42:1780-8.

8. Bernhard J, Zahrieh D, Castiglione-Gertsch M, Hurny C, Gelber RD, Forbes JF, et al. Adjuvant chemotherapy followed by goserelin compared with either modality alone: the impact on amenorrhea, hot flashes, and quality of life in premenopausal patients--the International Breast Cancer Study Group Trial VIII. J Clin Oncol. 2007;25:263-70.

9. de Haes H, Olschewski M, Kaufmann M, Schumacher M, Jonat W, Sauerbrei W, et al. Quality of life in goserelin-treated versus cyclophosphamide + methotrexate + fluorouraciltreated premenopausal and perimenopausal patients with node-positive, early breast cancer: the Zoladex Early Breast
Cancer Research Association Trialists Group. J Clin Oncol. 2003;21: 4510-6.

10. Nystedt M, Berglund G, Bolund C, Fornander T, Rutqvist LE. Side effects of adjuvant endocrine treatment in premenopausal breast cancer patients: a prospective randomized study. J Clin Oncol. 2003;21:1836-44.

11. Hurny C, Bernhard J, Coates AS, Castiglione-Gertsch M, Peterson HF, Gelber RD, et al. Impact of adjuvant therapy on quality of life in women with node-positive operable breast cancer. International Breast Cancer Study Group. Lancet. 1996;347:1279-84.

12. Bernhard J, Zahrieh D, Coates AS, Gelber RD, CastiglioneGertsch M, Murray E, et al. Quantifying trade-offs: quality of life and quality-adjusted survival in a randomised trial of chemotherapy in postmenopausal patients with lymph nodenegative breast cancer. Br J Cancer. 2004;91:1893-901.

13. Roche H, Kerbrat P, Bonneterre J, Fargeot P, Fumoleau P, Monnier A, et al. Complete hormonal blockade versus epirubicin-based chemotherapy in premenopausal, one to three node-positive, and hormone-receptor positive, early breast cancer patients: 7-year follow-up results of French Adjuvant Study Group 06 randomised trial. Ann Oncol. 2006;17:1221-7.

14. Kim HJ, Lee JS, Park EH, Lim WS, Sei JY, Koh BS, et al. Short term results from GHRH analogue use in pre-menopausal breast cancer in Korea. Eur J Surg Oncol. 2009;35:936-41.

15. Kaufmann M, Jonat W, Blamey R, Cuzick J, Namer M, Fogelman I, et al. Survival analyses from the ZEBRA study: goserelin (Zoladex) versus CMF in premenopausal women with node-positive breast cancer. Eur J Cancer. 2003;39:1711-7.

16. International Breast Cancer Study Group (IBCSG), Castiglione-Gertsch M, O'Neill A, Price KN, Goldhirsch A, Coates AS, et al. Adjuvant chemotherapy followed by goserelin versus either modality alone for premenopausal lymph node-negative breast cancer: a randomized trial. J Natl Cancer Inst. 2003;95:1833-46.

17. Shiba E, Yamashita H, Kurebayashi J, Noguchi S, Iwase H, Ohashi $Y$, et al. A randomized controlled study evaluating safety and efficacy of leuprorelin acetate every-3-months depot for 2 versus 3 or more years with tamoxifen for 5 years as adjuvant treatment in premenopausal patients with endocrine-responsive breast cancer. Breast Cancer. 2016;23: 499-509.

18. Boccardo F, Rubagotti A, Amoroso D, Mesiti M, Romeo D, Sismondi $\mathrm{P}$, et al. Cyclophosphamide, methotrexate, and fluorouracil versus tamoxifen plus ovarian suppression as 
adjuvant treatment of estrogen receptor-positive pre-/ perimenopausal breast cancer patients: results of the Italian Breast Cancer Adjuvant Study Group 02 randomized trial. J Clin Oncol. 2000;18:2718-27.

19. Jakesz R, Hausmaninger H, Kubista E, Gnant M, Menzel C, Bauernhofer T, et al. Randomized adjuvant trial of tamoxifen and goserelin versus cyclophosphamide, methotrexate, and fluorouracil: evidence for the superiority of treatment with endocrine blockade in premenopausal patients with hormoneresponsive breast cancer: Austrian Breast and Colorectal Cancer Study Group Trial 5. J Clin Oncol. 2002;20:4621-7.

20. Roche H, Mihura J, de Lafonta B, Reme-Saumon M, Martel P, Dubois J, et al. Castration and tamoxifen versus chemotherapy (FAC) for premenopausal, node negative, recpetor positive breast cancer patients: a randomized trail with a 7 years median follow-up. Proc Am Soc Clin Oncol. 1996;15:117.

21. Swain SM, Jeong JH, Geyer CE Jr, Costantino JP, Pajon ER, Fehrenbacher L, et al. Longer therapy, iatrogenic amenorrhea, and survival in early breast cancer. N Engl J Med. 2010;362: 2053-65.
22. Early Breast Cancer Trialists' Collaborative Group (EBCTCG). Effects of chemotherapy and hormonal therapy for early breast cancer on recurrence and 15-year survival: an overview of the randomised trials. Lancet. 2005;365:1687-717.

23. LHRH-agonists in Early Breast Cancer Overview Group, Cuzick J, Ambroisine L, Davidson N, Jakesz R, Kaufmann M, et al. Use of luteinising-hormone-releasing hormone agonists as adjuvant treatment in premenopausal patients with hormonereceptor-positive breast cancer: a meta-analysis of individual patient data from randomised adjuvant trials. Lancet. 2007; 369:1711-23.

24. Goldhirsch A, Gelber RD, Castiglione M. The magnitude of endocrine effects of adjuvant chemotherapy for premenopausal breast cancer patients. The International Breast Cancer Study Group. Ann Oncol. 1990;1:183-8.

25. Bianco AR, Del Mastro L, Gallo C, Perrone F, Matano E, Pagliarulo C, et al. Prognostic role of amenorrhea induced by adjuvant chemotherapy in premenopausal patients with early breast cancer. Br J Cancer. 1991;63:799-803. 